This paper is in press with Work Employment and Society 2002.

Attitudes Towards Work and Motherhood Held By Working and Non-working Mothers.

\author{
Gillian Marks and Diane M. Houston \\ Department of Psychology \\ University of Kent at Canterbury
}

Correspondence to: Dr Gillian Marks, Department of

Psychology, Keynes College, University of Kent, Canterbury, CT2 7NP.

Email G.Marks@ukc.ac.uk

Fax: 01227- 827030 Phone: 01227- 823542 


\section{Attitudes Towards Work and Motherhood Held by Working and Non- working Mothers}

This study explored the attitudes of mothers who worked full-time, those who worked part-time, and those who did no paid work. The aim was to examine whether these women formed a homogeneous group in terms of their attitudes towards the roles of worker and mother, or whether their attitudes varied as a function of employment status. The responses of the 119 women who took part indicated that work commitment, negative experiences of motherhood, and childcare beliefs differed according to employment status. All women were however united in the view that motherhood is more important than work and that all women should be able to work across their lifespan. 
A recent study by the Office for National Statistics (Thair and Risdon 1999) reported that the economic participation of women with pre-school children has increased dramatically, from $45 \%$ in 1988 to $55 \%$ in 1998 . The majority $(65 \%)$ of working women with pre-school children work on a part-time basis (LFS 1998). Thus, at the beginning of the twenty-first century half of all women with pre-school children are in employment. The aim of the present study is to compare attitudes towards motherhood and work in mothers who work full-time, part-time and those who do no paid work.

Hakim (1991 1995) originally suggested that women might be divided into two groups, which represent personal choices about work and motherhood. One group comprises women who have a high level of commitment to their occupational role - represented by long-term work plans, almost continuous fulltime work, higher status and higher earnings than other women. The second group consists of women who prioritise their homemaker role over their occupational role and are mainly represented in lower paid and part-time work roles. Hakim (1995) also suggested that both part-time workers and women who are not in paid employment can be viewed as prioritising the domestic sphere above paid employment.

There has been considerable controversy around Hakim's conceptualisation of women's work orientations (e.g. Fagan and Rubery 1996: Ginn et al 1996: Crompton and Harris 1998). Crompton and Harris argued that work patterns of women are a product of their particular circumstances, opportunities and constraints and the choices they make in response to these. They suggested that work and home orientations might fluctuate according to occupation, life cycle and national context. 
Attitudes towards work and motherhood

More recently Hakim (2000) has produced a comprehensive statement on women's work orientations - Preference Theory. Preference theory states that women in affluent societies have a real choice between family work and market work. Hakim argues that women can be classified as home centred (20\%), adaptive (60\%), or, work-centred (20\%). She states:

"A minority of women have no interest in employment, careers, or economic independence and do not plan to work long term unless things go seriously wrong for them. Their aim is to marry as well as they can and give up paid employment to become full-time homemakers and mothers. The group includes highly educated women as well as those who do not get any qualifications.... In contrast, other women actively reject the sexual division of labour in the home, expect to work full-time and continuously throughout life, and prefer symmetrical roles for the husband and wife rather than separate roles. The third group is numerically dominant: women who are determined to combine employment and family work, so become secondary earners. They may work full-time early in life, but later switch to part-time jobs on a semipermanent basis, and/or to intermittent employment." (Hakim, 2000: 189)

Hakim argues that women who are work-centred will often choose to be childless or will have children "in the same ways as among men, as an expression of normality and a weekend hobby" (280). Further, that adaptive women are the only group who do not want to make a choice between work and family - they want both and "if they give priority to family or to paid work, it is a temporary emphasis rather than a lifetime commitment." (280) Only adaptive women are influenced by lifecycle changes, work and home-centred women remain committed to these domains across the lifespan. As a consequence, 
Attitudes towards work and motherhood

adaptive women are less likely to make significant achievements in the world of work because they prefer a balanced life.

Hakim (2000) notes that the theorising of social change has taken different directions within social science. Attitudes and values have traditionally been examined within social psychology, whereas sociologists and economists have focused on social structural, political and economic factors. She suggests that preference theory demands a change of emphasis in sociology - a move away from social structural factors toward the examination of preferences and values.

As social psychologists working in a sociological domain we are only too ready to rise to this challenge. In the present study we explore the attitudes of women who are mothers. Hakim (2000) suggested that even childless women may prioritise the domestic sphere. However, the present study focuses on mothers, rather than women in general. This is because we wanted to examine attitudes to, and experiences, of motherhood and childcare as well as work. Owing to their status as a mother, it could be argued that all the working women in our sample may fall into the adaptive category. Whilst this is possible, only $16 \%$ of women born in 1953 remained childless (ONS 2000). Therefore some women with children might be expected to fall within Hakim's work-centred category. More importantly we would like to suggest that within the adaptive category suggested by Hakim (2000) are women with very diverse attitudes and experience. In particular we hypothesise that amongst mothers, an important determinant of work behaviour may be their experience of motherhood and childcare. Only longitudinal research will determine whether women who are home or work-centred make an early conscious and deliberate effort to concentrate their lives in these domains. However, it may be that women who 
could be classified as adaptive may hold very diverse attitudes to, and experiences of, caring for children as well as different attitudes to work.

Demographic research into women's work behaviour has shown that women's work participation increases with the age of the youngest child. Also women who are older and/or have a long work history are more likely to return to work after they have children (Thair and Ridson 1999). Thus age of youngest child and years of work are also examined in our study.

Our study also explores personal, general and ideological beliefs. There is evidence from international research that young adults may experience conflicts in their ideological and personal views about work and family roles. Burke (1994) looked at the values, career, and life expectations of Canadian university business students. He found that that men and women attached equal importance to work, marital, parental and home-care roles. However, when their own personal hopes and beliefs about work, family and parental responsibilities were examined, traditional ideas about the division of labour began to emerge. In another Canadian study, Davey (1998) looked at the way 54 female senior high school students evaluated career and family roles. She found that this sample placed a high and equivalent value on both career and family roles. She also found that even the women who indicated a marked preference to care full-time for their children had a strong image of themselves as a career woman. These two Canadian studies suggest that traditional and egalitarian beliefs may co-exist and that ideological beliefs may not be as good a predictor of work orientation as personal attitudes and experience.

The psychological literature also suggests that people may hold ambivalent or conflicted attitudes (Kaplan 1972) and that people may hold positive and negative attitudes toward an entity simultaneously. This means that 
it can be important to examine both negative and positive attitudes separately rather than simply represent them as opposite ends of a continuum. When examining the attitudinal determinants of behaviour psychological research has shown that negative attitudes toward an entity may be qualitatively different from positive attitudes (e.g. Maio and Olson 2000).

In the present study positive and negative, as well as personal, general and ideological attitudes to motherhood, childcare and work were examined in women with dependent children.

\section{Method}

\section{Design}

A questionnaire survey was conducted to investigate attitudes and beliefs of mothers about work, motherhood, combining the two roles and the issues surrounding childcare.

\section{Participants}

A total of 293 questionnaires were distributed through nursery schools, mother and toddler groups and two large retailers in Kent. Of these, 119 were returned, giving a response rate of $40.6 \%{ }^{1}$. Instructions on the first page requested that respondents be women who had children. This provided a targeted sample of mothers, rather than a random sample of women.

\section{Materials}

The scales within the questionnaire were designed to measure attitudes towards motherhood and work. Responses were measured on a seven-point 
scale: One denoted "strongly agree" and seven denoted "strongly disagree". The scale structure was confirmed using principal components analysis with varimax rotation ${ }^{2}$. Where a clear factor structure was confirmed, the items were summed and averaged to create indices of each scale. Internal reliability was assessed using Cronbach's alpha to ensure that the items also formed a conceptually consistent scale. A number of single items about lifestyle choices were also included. The scale designed to examine the role of fathers as primary carers did not form a reliable scale, these items were included separately.

\section{General Attitudes}

General positive attitude towards motherhood. Two items: " In general being a mother is a fulfilling/rewarding experience".

General negative attitude towards motherhood. Five items:

"In general being a mother is exhausting/boring/socially isolating/emotionally draining/stressful".

General positive attitude towards work. Four items: "Becoming a worker is an essential part of a woman's development/gives a woman a positively valued status in our society"; "For a woman being a worker is a fulfilling/rewarding experience".

General negative attitude towards work. Three items: "In general, women find work exhausting/emotionally draining/stressful”.

\section{Personal attitudes}

Personal positive attitudes toward motherhood. Four items: " For me, motherhood is a happy/fulfilling/rewarding experience"; "I am a good mother". 
Attitudes towards work and motherhood

Personal negative attitudes toward motherhood. Four items: "For me, motherhood is an exhausting/stressful/socially isolating/emotionally draining experience".

Personal positive attitudes toward work. Four items: "For me, work is a happy/fulfilling/rewarding experience"; "I will am/would be successful in my working role".

Personal negative attitudes toward work. Three items: "For me, work is an exhausting/ stressful/emotionally draining experience".

General Attitudes to Combining Work and Motherhood

Mothers should have a choice about working. Two items: "Women with pre-school/school age children should work if they want to".

Mothers should work if it is a financial necessity. Two items; "Women with pre-school/school age children should work if they need to financially".

Combining work and motherhood benefits both roles. Two items: "Being a mother would make a woman a better worker" and "Being a worker would make a woman a better mother".

Combining work and motherhood damages both roles. Two items: "Being a mother would make a woman an inadequate worker" and "Being a worker would make a woman an inadequate mother".

Easy to combine work and motherhood. Two items: "It is easy/difficult to combine work and motherhood".

Personal Commitment to Work and Motherhood.

Commitment to work. Two items: "Being a worker is important to me" and "It is important to me to be a competent worker".

Commitment to motherhood. Two items: "Being a mother is important to me" and "It is important to me to be a competent mother". 


\section{Childcare.}

Mothers as primary carers. Three items: "Mothers should be the primary carers of their children", "Women are intuitively aware of the needs of their children" and "Women are naturally able to perform all childcare duties".

Mother and father primary care benefits. Four items measured how strongly the women agreed that the child would benefit in terms of their emotional and physical health and the development of their intellect and social skills.

Other care benefits. Four items measured respondent's beliefs that a pre-school child might benefit physically, emotionally, intellectually and socially from being placed in their most preferred childcare option.

Fathers as primary carers. These five items did not form a reliable scale, but were examined separately: "Men should be involved in childcare." "Men and women should share childcare equally." "It is alright for men to be the primary carers of their children." "Men are intuitively aware of the needs of their children." "Men are naturally able to perform all childcare duties, except for breast-feeding."

\section{Ideological beliefs}

Five separate items: "Motherhood is more important than work." "Motherhood and work are equally important." "Work is more important than motherhood." "All women should have the opportunity to work across their life-span." "It is socially unacceptable to combine work and motherhood."

\section{Procedure}

Questionnaire packs were distributed which contained a description of the survey and examples of how to complete the seven-point scales. The instructions 
asked the women to give their personal views and not to consult with others. They were assured of the anonymity of their responses.

\section{Results}

Employment.

One hundred and sixteen of the women gave information about their employment status, of these $26.7 \%(\underline{n}=31)$ were working full-time, $45.7 \%(\underline{n}=$ 53) were working part-time and $27.6 \%(\underline{n}=32)$ were doing no paid work ${ }^{3}$.

Social Class.

Social class was defined in terms of five groups according to the Standard Occupational Classification (OPCS 1991). All five social classes were represented in the sample. The majority fell within social classes two (managerial and technical occupations) and three (manual and non-manual skilled occupations). Social class was entered in each analysis but was not a significant predictor of employment category in this sample.

Age.

The mean age of the sample was $37.32,(\underline{\mathrm{S}}=7.61, \underline{\mathrm{N}}=117)$.

\section{Scale Means and Reliability}

Table One shows the reliability of each scale as measured by Cronbach's alpha. The means for each scale and means broken down by employment category are also shown. 


\section{Predicting the Employment Category}

Multinomial logistic regression was used to determine which variables discriminated each of the three groups defined according to employment status. The analysis was applied in two ways; first no paid work was used as the baseline category against which those doing full-time work and part-time work were compared. Second, women doing part-time work were used as the baseline category against which women doing full-time work and no paid work were compared. The exact number of cases in the following analyses varies because of outliers and randomly distributed missing data. In each case the attitude scales were entered into the analysis alongside years of work, social class and age of youngest child. In the tables that follow, positive beta weights indicate that the variable is positively associated with the outcome. Negative beta weights indicate that the variable is negatively associated with the outcome.

\section{Predicting Employment Status Using No Paid Work as the Baseline Category}

The use of no paid work as the baseline category produced a model which was significantly different from a constant only model: $\chi^{2}(12)=89.32, \underline{p}<$ .001. The Nagelkerke $R^{2}$ statistic showed it accounted for $65.5 \%$ of the variance. It predicted full-time work with $67.7 \%$ accuracy, part-time work with $86.5 \%$ accuracy and no paid work with $81.8 \%$ accuracy. The overall rate of predictive accuracy was $80.0 \%$.

When predicting full-time work against a baseline of doing no paid work the strongest predictor, according to the odds ratio, was work commitment (Table 2). The higher their work commitment, the more likely women were to work full-time. The next most important predictor of full-time work was personal 
Attitudes towards work and motherhood

negative attitudes toward motherhood. This indicates that full-time workers felt less negative about their experience of motherhood. The next most important predictors were mothers as primary-carers and other-care benefits. The less women agreed with the idea of a mother providing a unique role as a primary caregiver, the more likely they were to work full-time. The more women agreed that children might benefit from alternative child-care the more likely they were to work full-time.

Years of employment and age of youngest child were significant predictors: As years of employment increased, women were more likely to be working full-time and the older their youngest child the more likely they were to work full-time.

Part-timers could be distinguished from the base-line category of nonworkers by some of the same predictors as full-timers - work commitment, personal negative attitudes about motherhood, and, mothers as primary carers (Table 2).

Table 2 about here

Predicting Full-Time Employment Using Part-Time Work as the Baseline Category

Part-time work was used as the baseline category and full-time work was the predicted category. The final model was significantly different from a constant only model: $\chi^{2}(10)=82.79, \underline{p}<.001$. According to the Nagelkerke $\mathrm{R}^{2}$ statistic it accounted for $62.4 \%$ of the variance. It predicted full-time work with $67.7 \%$ accuracy, part-time work with $82.7 \%$ accuracy and no paid work with $68.2 \%$ accuracy. The overall rate of predictive accuracy was $75.2 \%$. 
The scale which most strongly distinguished full-time workers from parttime workers was work commitment (Table 3). Full-timers had higher levels of work commitment. In addition, when compared to part-timers, full-timers held less personal negative attitudes about motherhood, tended to have had a longer previous history of working, and to have older children.

Table 3 about here

The Relative Importance of Work and Motherhood

Four items were used to explore the relative importance of work and motherhood. Analysis of variance showed that there were no significant differences between the views of the three groups (See Table 1). All three groups tended to agree that motherhood is more important than work and to disagree with the idea that work is more important than motherhood. All three groups strongly agreed with the idea that women should have the opportunity to work across their life span.

\section{Discussion}

Our findings show that it was possible to discriminate between mothers who worked full-time, those who worked part-time, and those who were doing no paid work in terms of their work commitment and their attitudes to motherhood and childcare. Social class did not relate to work behaviour and the attitudinal variables accounted for additional variance even when the age of the youngest child and years of work were accounted for.

Mothers who were working, either part-time or full-time, could be distinguished from those who were not in employment on the basis of three 
attitude scales. The strongest attitudinal discriminator was the woman's strength of work commitment. Those who were in paid employment had higher scores on this scale. A dispositional level of work commitment may therefore drive work behaviour. Alternatively, it could be argued that it is difficult for women who are not in work to maintain high levels of work commitment because they have relinquished their personal identity as a worker. This may be part of the barrier women face when they consider returning to paid employment.

The second most influential scale that distinguished women who were doing paid work was personal negative attitudes to motherhood. All of the women in our sample were mothers, but positive aspects of motherhood did not differentiate between groups. It was their negative views about motherhood that discriminated between workers and those doing no paid work. Those who were working agreed less strongly that motherhood was a boring, exhausting, stressful and socially isolating experience.

Women who were in paid employment also agreed less strongly that mothers should be the primary carers of their children and that women are naturally or intuitively equipped to do so.

The concept of 'other care benefits' also distinguished full-time workers from those who were not in paid employment. This item was asked in reference to the individual's most preferred childcare option. The power of this predictor rested on the fact that while non-workers tended to disagree that a child might benefit from alternative childcare, and part-timers scored around the mid-point, full-timers tended to agree that children might benefit from alternative forms of child-care. This finding may be linked to the idea that those who remain at home with their children regard the mother's role as crucial to the child's 
upbringing - they do not think that anyone but themselves can provide the type and quality of care they want for their child.

Years of work also distinguished full-timers, but not part-timers, from non-workers. The longer the work experience the more likely the women were to work full-time.

Women who worked full-time and those who worked part-time could also be distinguished on the basis of their work commitment. While age of youngest child and years of work did play a part in the division of full-time and part-time workers, the strongest discriminator was work commitment. The higher the work commitment, the more likely they were to work full-time rather than part-time. This suggests that these women combined full-time work with motherhood because their working role was an important part of their self-identity. Fulltimers could also be distinguished from part-timers on the basis of their negative attitudes to motherhood. Full-timers agreed less strongly that there were negative aspects to motherhood.

Whilst the mothers could be differentiated on the basis of some of their attitudes it is also important to note that their views on many aspects of work and motherhood did not differ significantly. This is particularly true of their ideological views. All three groups agreed that motherhood is more important than work. All three groups disagreed that work is more important than motherhood. The mothers in this study, independent of work status, tended to place a high value on motherhood relative to their working role. However they all agreed strongly that every woman should have the right to work across their lifespan. This suggests that women who might be categorised as home-centred still supported the idea that a working role is important for women. 
Attitudes towards work and motherhood

The findings from the present study do in many ways support Hakim's (2000) categorisation of women. Our findings indicate that one reason why women work is their commitment to a working role. Perhaps most interesting, is the way in which negative attitudes to mothering are related to women's work behaviour independently of work commitment. Mothers who were not working, and those who were working part-time agreed more strongly that they found aspects of motherhood boring, exhausting, stressful and socially isolating. Women who work full-time feel less strongly that motherhood has a negative component. It seems that time spent in work has a positive effect on the way women feel about their maternal role. Hakim (2000) argues that women form intentions and make choices about the way in which they divide their commitment between work and family. The present study shows that women's ongoing experiences of childcare and caring for children may also determine their participation in work.

Rose (2000) did not find substantial differences in the levels of work commitment of women who worked part and full-time. He also found that level of work commitment amongst full-time workers and homemakers varied according to their future intentions in relation to work. Rose's analysis was from the SCELI data in which the measure of work commitment was the "lottery question' - the proportion saying they would continue to hold paid work, would continue to seek it, or would continue wishing to return to it, even if the financial need to do so was removed. In the present study work commitment was measured using items from the psychological literature that specifically reflect personal commitment to the working role rather than a (perhaps improbable) choice between a life of work and a life of affluence and leisure. Future research 
should address the measurement of work commitment in order to determine which concepts most accurately reflect psychological commitment to work.

For mothers of dependent children the decision to work may be shaped by an enormous number of factors whether demographic, social, economic or psychological. In addition, the demands of work and childcare may have different consequences for different women. The present study has shown that women who do no paid work, those who work part-time, and those who work full-time, hold different attitudes to both motherhood and work. However they also share many attitudes and ideological beliefs. Whether the differences arise from different long-term intentions or from different experiences and opportunities can only begin to be examined by longitudinal research that begins before women become mothers (Houston and Marks 2000). 


\section{References}

Burke, R. J. (1994) 'Career and life values and expectations of university business students', Psychological Reports, 75 (1) 147-160.

Crompton, R and Harris, F. (1998) 'Explaining women's employment patterns: orientations to work revisited', British journal of Sociology, 30, 427-425.

Davey, F. H. (1998) 'Young Women's Expected and Preferred Patterns of Employment and Child Care', Sex Roles, 38 (1/2), 95-102.

Fagan, C. and Rubery, J. (1996) 'The salience of the part-time divide in the European Union', European Sociological Review, 12, 227-250.

Ginn, J., Arber, S., Brannen, J., Dale, A., Dex, S., Elias, P., Moss, P., Pahl, J., Roberts, C. and Rubery, C. (1996) 'Feminist Fallacies: a reply to Hakim on women's employment', British Journal of Sociology, 47, 1, 167-174.

Hakim, C. (1991) 'Grateful slaves and self-made women: Fact and fantasy in women's work orientations', European Sociological Review, 7, 2, 101121.

Hakim, C. (1995) 'Five feminist myths about women's employment', The British Journal of Sociology, 46, 3, 429-455.

Hakim, C. (2000) Work-Lifestyle Choices in the $21^{\text {st }}$ Century: Preference Theory. OUP.

Houston, D.M. and Marks, G. (2000) 'Employment Choices for Mothers of Pre School Children: A Psychological Perspective', End of Award Report to ESRC.

Kaplan, K.L. (1972) 'On the ambivalence-indifference problem in attitude theory and measurement: A suggested modification of the semantic differential technique', Journal of Experimental Social Psychology, 33, 190-210. 
Attitudes towards work and motherhood

Kinder, D. R., and Sears, D. O. (1985) 'Public opinion and political action', in G. Lindzey \& E. Aronson (eds.), Handbook of Social Psychology ( ${ }^{\text {rd }}$ ed, Vol. 2, (659-741). New York: Random House.

LFS (1998) Labour Force Survey. Office of National Statistics. Spring.

Maio, G. R. and Olson, J. M. (eds.) (2000) Why we evaluate: Functions of attitudes. Mahwah, NJ US, Lawrence Erlbaum Associates.

ONS (2000) Men and Women in the UK. The Women's Unit.

OPCS (1991) Social Occupational Classification, Vol. 1, 2, and 3, Office of Population Census Surveys. London: HMSO.

Rose, M. (2000) Housework, Employment Plans and Women's Work Attitudes. ESRC Working Paper 5.

Thair, T. and Risdon, A. (1999) 'Women in the labour market: results from the Spring 1998 LFS', Labour Market Trends, March. UK HMSO. 
Table 1: Summary of Attitudinal Scales

\begin{tabular}{|c|c|c|c|c|c|c|c|c|}
\hline \multirow[t]{2}{*}{ Attitudinal Scales } & \multirow[t]{2}{*}{ Alpha } & \multirow[t]{2}{*}{ Mean (SD) } & \multicolumn{2}{|c|}{ Full-time Work $(n=31)$} & \multicolumn{2}{|c|}{ Part-time Work $(n=53)$} & \multicolumn{2}{|c|}{ No Paid Work $(n=32)$} \\
\hline & & & Mean & SD & Mean & SD & Mean & SD \\
\hline General positive motherhood & .77 & $1.84(.97)$ & 1.86 & 1.23 & 1.94 & .81 & 1.65 & .92 \\
\hline General negative motherhood & .70 & $3.34(1.01)$ & 3.39 & 1.20 & 3.48 & .94 & 3.08 & .91 \\
\hline General positive work & .67 & $2.98(.93)$ & 2.85 & 1.12 & 3.11 & .78 & 2.89 & .96 \\
\hline General negative work & .78 & $3.12(.99)$ & 3.18 & 1.21 & 3.20 & .89 & 2.94 & .93 \\
\hline Personal positive motherhood & .85 & $1.90(.78)$ & 1.83 & .90 & 1.91 & .70 & 1.91 & .81 \\
\hline Personal negative motherhood & .80 & $3.25(1.25)$ & 3.73 & 1.44 & 3.29 & 1.13 & 2.68 & 1.02 \\
\hline Personal positive work & .88 & $1.99(.79)$ & 1.85 & .87 & 2.05 & .78 & 1.99 & .74 \\
\hline Personal negative work & .82 & $3.75(1.33)$ & 3.43 & 1.44 & 4.02 & 1.22 & 3.59 & 1.33 \\
\hline Should have choice about work & .76 & $1.93(1.21)$ & 1.61 & 1.04 & 1.92 & 1.15 & 2.27 & 1.39 \\
\hline Work if financial necessity & .88 & $2.26(1.43)$ & 2.29 & 1.45 & 2.15 & 1.31 & 2.42 & 1.60 \\
\hline Combining benefits both roles & .71 & $4.06(1.41)$ & 3.53 & 1.45 & 4.03 & 1.19 & 4.63 & 1.53 \\
\hline Combining damages both roles & .74 & $6.29(1.14)$ & 6.34 & 1.37 & 6.43 & .79 & 6.03 & 1.37 \\
\hline Easy to combine both roles & .88 & $5.43(1.46)$ & 5.24 & 1.67 & 5.12 & 1.50 & 6.11 & 1.01 \\
\hline Commitment to work & .62 & $2.32(1.23)$ & 1.63 & .83 & 2.19 & 1.07 & 3.22 & 1.30 \\
\hline Commitment to motherhood & .67 & $1.24(.52)$ & 1.31 & .72 & 1.26 & .47 & 1.13 & .34 \\
\hline Mothers as primary carers & .72 & $3.53(1.47)$ & 3.76 & 1.75 & 3.66 & 1.36 & 3.08 & 1.28 \\
\hline Mother care benefits & .91 & $3.35(1.39)$ & 3.23 & 1.57 & 3.48 & 1.36 & 3.24 & 1.26 \\
\hline Father care benefits & .91 & $3.65(1.30)$ & 3.77 & 1.41 & 3.56 & 1.35 & 3.68 & 1.08 \\
\hline Other care benefits & .90 & $4.20(1.53)$ & 3.61 & 1.63 & 4.10 & 1.49 & 4.95 & 1.19 \\
\hline Men should be involved in child care & - & $1.30(.74)$ & 1.16 & .37 & 1.32 & .92 & 1.41 & .67 \\
\hline Should share child care equally & - & $2.48(1.49)$ & 1.94 & 1.36 & 2.62 & 1.52 & 2.78 & 1.41 \\
\hline Alright for men to be primary carer & - & $2.32(1.55)$ & 2.42 & 1.80 & 2.17 & 1.41 & 2.47 & 1.52 \\
\hline Men intuitively aware of child's needs & - & $4.09(1.31)$ & 4.06 & 1.48 & 4.04 & 1.33 & 4.19 & 1.12 \\
\hline Men naturally able to do child care & - & $3.70(1.82)$ & 3.97 & 1.94 & 3.47 & 1.85 & 3.81 & 1.67 \\
\hline Motherhood more important than work & - & $2.63(1.90)$ & 3.23 & 2.20 & 2.53 & 1.72 & 2.22 & 1.81 \\
\hline Motherhood \& work equally important & - & $4.50(1.91)$ & 3.90 & 2.10 & 4.47 & 1.79 & 5.00 & 1.81 \\
\hline Work more important than motherhood & - & $6.02(1.22)$ & 5.84 & 1.39 & 5.98 & 1.20 & 6.25 & 1.05 \\
\hline Opportunity to work across life-span & - & $1.47(.80)$ & 1.39 & .80 & 1.57 & .87 & 1.38 & .66 \\
\hline Socially unacceptable to combine & - & $5.24(1.61)$ & 5.03 & 1.85 & 5.68 & 1.41 & 4.72 & 1.51 \\
\hline
\end{tabular}


Table 2: Predicting full-time and part-time employment, with no paid work as the baseline category $(\underline{\mathrm{N}}=105)$.

\begin{tabular}{|c|c|c|c|c|c|c|}
\hline Behaviour & Construct & B & Wald & $\begin{array}{l}\text { Odds } \\
\text { Ratio }\end{array}$ & $\begin{array}{l}95 \% \\
\text { Lower } \\
\text { Bound }\end{array}$ & $\begin{array}{l}95 \% \text { Upper } \\
\text { Bound }\end{array}$ \\
\hline \multirow[t]{6}{*}{ Full-time work } & Work commitment & -1.89 & $12.79^{\star \star \star}$ & .15 & .05 & .42 \\
\hline & $\begin{array}{l}\text { Negative attitudes } \\
\text { motherhood }\end{array}$ & 1.32 & $8.25^{\star *}$ & 3.73 & 1.52 & 9.17 \\
\hline & $\begin{array}{l}\text { Mothers primary } \\
\text { carers }\end{array}$ & .96 & $6.21^{*}$ & 2.62 & 1.23 & 5.60 \\
\hline & Other-care benefits & -.85 & $5.62^{*}$ & .43 & .21 & .86 \\
\hline & Years of work & .50 & $6.55^{\star *}$ & 1.65 & 1.12 & 2.41 \\
\hline & $\begin{array}{l}\text { Age of youngest } \\
\text { child }\end{array}$ & .48 & $15.97^{* \star *}$ & 1.61 & 1.28 & 2.04 \\
\hline \multirow{4}{*}{$\begin{array}{l}\text { Part-time } \\
\text { work }\end{array}$} & Work commitment & -.86 & $5.19^{*}$ & .43 & .20 & .89 \\
\hline & $\begin{array}{l}\text { Negative attitudes } \\
\text { motherhood }\end{array}$ & .81 & $4.73^{*}$ & 2.25 & 1.08 & 4.67 \\
\hline & $\begin{array}{l}\text { Mothers as primary } \\
\text { carers }\end{array}$ & .67 & $3.95^{*}$ & 1.95 & 1.01 & 3.77 \\
\hline & $\begin{array}{l}\text { Age of youngest } \\
\text { child }\end{array}$ & .29 & $7.54^{* *}$ & 1.34 & 1.09 & 1.65 \\
\hline
\end{tabular}


Table 3: Predicting full-time employment using part-timers as the baseline category ( $\underline{\mathrm{N}}$ $=114^{1}$ ).

\begin{tabular}{|c|c|c|c|c|c|c|}
\hline Behaviour & Construct & $B$ & Wald & $\begin{array}{l}\text { Odds } \\
\text { Ratio }\end{array}$ & $\begin{array}{l}95 \% \\
\text { Lower } \\
\text { bound }\end{array}$ & $\begin{array}{l}95 \% \\
\text { Upper } \\
\text { bound }\end{array}$ \\
\hline \multirow{4}{*}{$\begin{array}{l}\text { Full-time } \\
\text { work }\end{array}$} & Work commitment & 1.20 & $10.05^{* \prime}$ & .30 & .14 & .63 \\
\hline & $\begin{array}{l}\text { Negative attitudes } \\
\text { motherhood }\end{array}$ & .52 & $3.81^{*}$ & 1.68 & .99 & 2.83 \\
\hline & Years of work & .36 & $6.72^{\star *}$ & 1.43 & 1.09 & 1.88 \\
\hline & $\begin{array}{l}\text { Age of youngest } \\
\text { child }\end{array}$ & .15 & $9.34^{* *}$ & 1.68 & 1.06 & 1.29 \\
\hline
\end{tabular}




\footnotetext{
${ }^{1}$ Questionnaires were not administered directly to people - packs containing questionnaires were left beneath a poster that described the survey. It is likely that the response rate reflects the fact that some people took a questionnaire pack and then subsequently decided they did not meet the criteria - for example they may have been grandparents.

${ }^{2}$ Principal Components Analysis was used because it is the method of choice when the aim is to reduce a large number of variables down to a smaller number of components and it is the recommended first step in when examining the probable number and nature of factors in a data set (Tabachnick and Fidell, 1996, p. 664). There is some debate about the sample size required for Principal Components Analysis. Kline (1994, p73) suggests that a sample of 100 is sufficient where there is a clear factor structure. The bigger the sample the more confidently one might extrapolate to a wider population. In the present study the analysis was done on a confirmatory rather than exploratory basis and thus the sample size can be considered adequate.

${ }^{3}$ Hereafter referred to as full-timers, part-timers and non-workers for the sake of brevity, although it is recognised that many of the tasks that women perform in the home are work.
} 